\title{
Diatomáceas perifíticas abundantes em três córregos com diferentes ações antrópicas em Maringá, PR, Brasil
}

\author{
CARINA MORESCO ${ }^{1}$, PRISCILA IZABEL TREMARIN² ${ }^{2}$ THELMA ALVIM VEIGA LUDWIG² e \\ LILIANA RODRIGUES ${ }^{1,3}$
}

(recebido: 13 de maio de 2010; aceito: 30 de junho de 2011)

\begin{abstract}
Abundant periphytic diatoms in three streams with different anthropic influences in Maringá, Paraná State, Brazil). A taxonomic study is presented of the predominant periphytic diatoms from three streams, Nazaré, Guaiapó and Remo, influenced by different anthropogenic actions. Samples were taken bimonthly in three sites of the stream watercourse, headwater, middle and mouth, from July 2007 to August 2008. Twenty six predominant species was recorded, from a total of 151 identified diatoms in the analyzed samples. Seven species were abundant or dominant in the three studied streams: Eolimna minima (Grunow) Lange-Bertalot (dominant in Remo stream), Gomphonema lagenula Kützing (dominant in Guaiapó stream), Gomphonema pumilum (Grunow) Reichardt \& Lange-Bertalot and Nupela praecipua (Reichardt) Reichardt (both dominant in Nazaré stream), Geissleria aikenensis (Patrick) Torgan \& Oliveira, Nitzschia palea (Kützing) Smith and Sellaphora seminulum (Grunow) Mann (abundant in three streams). Two species were abundant exclusively in Nazaré urban stream, 13 in Remo rural streams and six in Guaiapó stream that is influenced by both environments.
\end{abstract}

Key words - algae, lotic ecosystem, river basin, taxonomy

RESUMO - (Diatomáceas perifíticas abundantes em três córregos com diferentes ações antrópicas em Maringá, PR, Brasil). Realizou-se o estudo taxonômico das diatomáceas perifíticas predominantes em três córregos, Nazaré, Guaiapó e Remo, influenciados por diferentes ações antrópicas. As coletas foram bimestrais, contemplando três locais dos córregos, cabeceira, meio e foz, no período de julho de 2007 a agosto de 2008. Foram registradas 26 espécies predominantes entre as 151 diatomáceas determinadas nas amostras. Sete espécies foram abundantes ou dominantes nos três córregos estudados: Eolimna minima (Grunow) Lange-Bertalot (dominante no Córrego Remo), Gomphonema lagenula Kützing (dominante no Córrego Guaiapó), Gomphonema pumilum (Grunow) Reichardt \& Lange-Bertalot e Nupela praecipua (Reichardt) Reichardt (dominantes no Córrego Nazaré), Geissleria aikenensis (Patrick) Torgan \& Oliveira, Nitzschia palea (Kützing) Smith e Sellaphora seminulum (Grunow) Mann (abundantes nos três córregos). Duas espécies foram abundantes exclusivamente no Córrego Nazaré urbano, 13 no Córrego Remo rural e quatro no Córrego Guaiapó que sofre influência de ambos ambientes.

Palavras-chave - alga, bacia hidrográfica, ecossistema lótico, taxonomia

\section{Introdução}

O crescimento desordenado da população gera um rápido processo de urbanização, com várias consequências que se refletem na qualidade da água dos corpos hídricos (Allan \& Castillo 2007, Ramírez et al. 2008). A falta de rede coletora e de tratamento de efluentes domésticos e industriais e uso indiscriminado de herbicidas e fertilizantes nas plantações são os principais fatores envolvidos, no caso dos ambientes lóticos (Walsh 2000, Kannel et al. 2007).

A utilização das diatomáceas em estudos de monitoramento da qualidade da água de rios e riachos

1. Universidade Estadual de Maringá, Programa de Pós-graduação em Ecologia de Ambientes Aquáticos Continentais, Núcleo de Pesquisas em Limnologia, Ictiologia e Aquicultura, Av. Colombo, 5790, 87020-900 Maringá, PR, Brasil.

2. Universidade Federal do Paraná, Departamento de Botânica, Caixa Postal 19031, Centro Politécnico, 81531-990 Jardim das Américas, Curitiba, PR, Brasil.

3. Autor para correspondência: lrodrigues@nupelia.uem.br iniciou-se na década passada e é rotineira em muitos países (Whitton \& Kelly 1995, Kelly et al. 1998, Hall \& Smol 1999, Gómez \& Licursi 2001, Ács et al. 2005, Potapova \& Charles 2007, Stenger-Kovács et al. 2007). No Brasil, trabalhos com este enfoque restringem-se aos realizados na região sul (Lobo et al. 2002, Lobo et al. 2004, Salomoni et al. 2006). Geralmente abundante nos ecossistemas aquáticos, este grupo de algas silíceas apresenta atributos que as tornam excelentes bioindicadores das condições da água, respondendo prontamente às alterações ambientais (Stevenson \& Pan 1999). O curto ciclo de vida, a ocorrência em abundância e diversidade ao longo de todo o rio, a sensibilidade específica a alterações e distúrbios ambientais, a facilidade de amostragem, preservação e distribuição para outros laboratórios, são destacados (Growns 1999, Stevenson \& Pan 1999, Lobo et al. 2002). Entretanto, a eficácia dos estudos de avaliação ambiental depende de uma taxonomia acurada, nem sempre de fácil execução (McCormick \& Cairns 1994, Sheath \& Wehr 
2003), pois exige pessoal bem treinado para realizar as identificações, baseadas nos inúmeros e diversificados detalhes da frústula.

Trabalhos taxonômicos sobre as diatomáceas de ecossistemas lóticos brasileiros têm sido pouco frequentes considerando-se a extensão da rede hidrográfica do país. Contribuições mais numerosas foram disponibilizadas por pesquisadores do estado paranaense, sendo as mais recentes: Landucci \& Ludwig (2005), Ferrari \& Ludwig (2007), Tremarin et al. (2008a, 2008b, 2009, 2010).

Pouco se conhece sobre a diatomoflórula do Município de Maringá. Apenas dois trabalhos taxonômicos foram realizados em ambientes lóticos. Train (1991) encontrou sete táxons de diatomáceas no córrego Moscados e Leandrini et al. (2002), em estudo realizado no Rio Pirapó e no Córrego Sarandi, registraram 20 táxons do gênero Navicula Bory.

O objetivo deste trabalho foi realizar o estudo taxonômico das diatomáceas perifíticas abundantes e/ou dominantes em três córregos localizados no município de Maringá, PR, cujas microbacias apresentam diferenças na ocupação do solo.

\section{Material e métodos}

Área de estudo - A bacia hidrográfica do Rio Pirapó enquadrase no grande sistema do Rio Paraná, sendo importante afluente da margem sul (esquerda) do Rio Paranapanema (Maack 2002). Esta região fisiográfica é denominada Terceiro Planalto Paranaense, especificamente no polígono delimitado pelas latitudes de $22^{\circ} 30^{\prime}$ e $23^{\circ} 30^{\prime}$ Sul, e longitudes de $51^{\circ} 15^{\prime}$ e $52^{\circ} 15^{\prime}$ Oeste, com uma área de drenagem de aproximadamente $5.076 \mathrm{~km}^{2}$. O clima predominante na região é subtropical, assegurando chuvas abundantes no verão e inverno seco, com temperaturas médias anuais superiores a $20{ }^{\circ} \mathrm{C}$ (Peruço 2004).

As águas dessa bacia hidrográfica são de grande importância em relação à captação para o abastecimento, desenvolvimento de atividades agropecuárias e turismo ecológico da grande maioria das cidades da região (Peron et al. 2009). Nesse ambiente, devido ao desmatamento desenfreado, conseqüência da rápida colonização e do contínuo crescimento urbano, tem se registradas gradativas alterações climáticas, as quais são refletidas sobre o ciclo hidrológico local (Peruço 2004).

O Município de Maringá está localizado sobre o divisor de águas das bacias dos Rios Pirapó e Ivaí e abrange diversas nascentes no perímetro urbano (Queiroz 2003). A região é relativamente industrializada e urbanizada, sendo a cidade de Maringá o centro urbano mais importante da região, com cerca de 300 mil habitantes (Peruço 2004).

As microbacias dos córregos amostrados apresentam diferenças no uso do solo, sendo que o Córrego Nazaré $\left(23^{\circ} 25^{\prime} 08,47^{\prime \prime} \mathrm{S} ; \quad 51^{\circ} 57^{\prime} 40,10^{\prime \prime} \mathrm{W} \quad\right.$ a $\quad 23^{\circ} 23^{\prime} 09,12^{\prime \prime} \mathrm{S}$; $51^{\circ} 58^{\prime} 01,62^{\prime}$ W) apresenta seu curso inteiramente no perímetro urbano, com ocupação residencial, recebendo galerias pluviais e esgoto doméstico. O Córrego Guaiapó $\left(23^{\circ} 24^{\prime} 52,18^{\prime \prime} \mathrm{S} ; \quad 51^{\circ} 52^{\prime} 33,24^{\prime \prime} \mathrm{W}\right.$ a $23^{\circ} 23^{\prime} 09,12^{\prime \prime} \mathrm{S}$; $51^{\circ} 58^{\prime} 01,62$ "W) possui cabeceira na zona urbana, com ocupação residencial e industrial, e a foz está localizada na zona rural com rotação de culturas (milho, soja e trigo). O Córrego Remo $\left(23^{\circ} 22^{\prime} 19,45^{\prime \prime} \mathrm{S}\right.$; 52 $2^{\circ} 01^{\prime} 15,70^{\prime \prime} \mathrm{W}$ a $23^{\circ} 20^{\prime} 51,94^{\prime \prime} \mathrm{S} ; \quad 50^{\circ} 00^{\prime} 50,43^{\prime \prime} \mathrm{W}$ ) é totalmente rural, apresentando o desenvolvimento das mesmas culturas ao longo do seu percurso (figura 1).

Amostragem e coleta das diatomáceas - no período de julho de 2007 a agosto de 2008 foram feitas coletas bimestrais nos Córregos Nazaré, Guaiapó e Remo, situados no Município de Maringá, PR (figura 1). Em cada córrego as amostragens contemplaram três locais de coleta: cabeceira, meio e foz.

Em cada período também foram obtidos $\mathrm{pH}$ e condutividade elétrica, utilizando-se equipamentos analíticos portáteis (medidor de pH Digimed DM-22 e condutivímetro Digimed DM-32, respectivamente). Para a avaliação da demanda bioquímica de oxigênio $\left(\mathrm{DBO}_{5}\right)$, amostras de água foram analisadas pelo laboratório de Saneamento e Agroquímica da Universidade Estadual de Maringá, seguindo a metodologia utilizada pela Cetesb (Companhia de Tecnologia e Saneamento Ambiental de São Paulo), L5.120 - demanda bioquímica de oxigênio, método de diluição e incubação $\left(20^{\circ} \mathrm{C}, 5\right.$ dias $)$ (Cetesb 1991).

Para as análises quali e quantitativas das comunidades, foram amostrados três seixos em cada local de coleta e a média da área total raspada foi $50 \mathrm{~cm}^{2}$. Este substrato foi escolhido por ser o mais abundante e estar presente em todos os pontos de amostragem. A face oposta à direção da corrente foi raspada com auxílio de escova e lâmina de barbear e o material recolhido foi fixado com formalina $4 \%$ (proporção $1: 1)$. Foram tomadas medidas da área da superfície raspada utilizando-se um paquímetro. $\mathrm{O}$ material foi oxidado com $\mathrm{KMnO}_{4}$ e HCl, de acordo com a técnica de Simonsen (1974), modificada por Moreira Filho \& Valente-Moreira (1981). O material oxidado foi seco sobre um suporte de alumínio revestido por paládio para a análise em microscópio eletrônico de varredura (MEV) modelo JEOL-6360LV, operado a $15 \mathrm{kV}$. A resina utilizada para a montagem das lâminas permanentes foi Hyrax. As lâminas foram depositadas no Herbário da Universidade Estadual de Maringá (HUEM).

Os indivíduos foram identificados e contados em microscópio óptico Olympus CX31, até que um mínimo de 600 valvas fosse registrado, conforme recomendações de Kobayasi \& Mayama (1982), com uma eficiência de contagem de 90\% (Pappas \& Stormer 1996). As espécies abundantes e dominantes foram determinadas de acordo com o critério de Lobo \& Leighton (1986), que consideram abundantes aquelas espécies cujas densidades superam a densidade média da amostra e dominantes aquelas espécies cujas densidades superam $50 \%$ da densidade total da amostra. Para o presente 


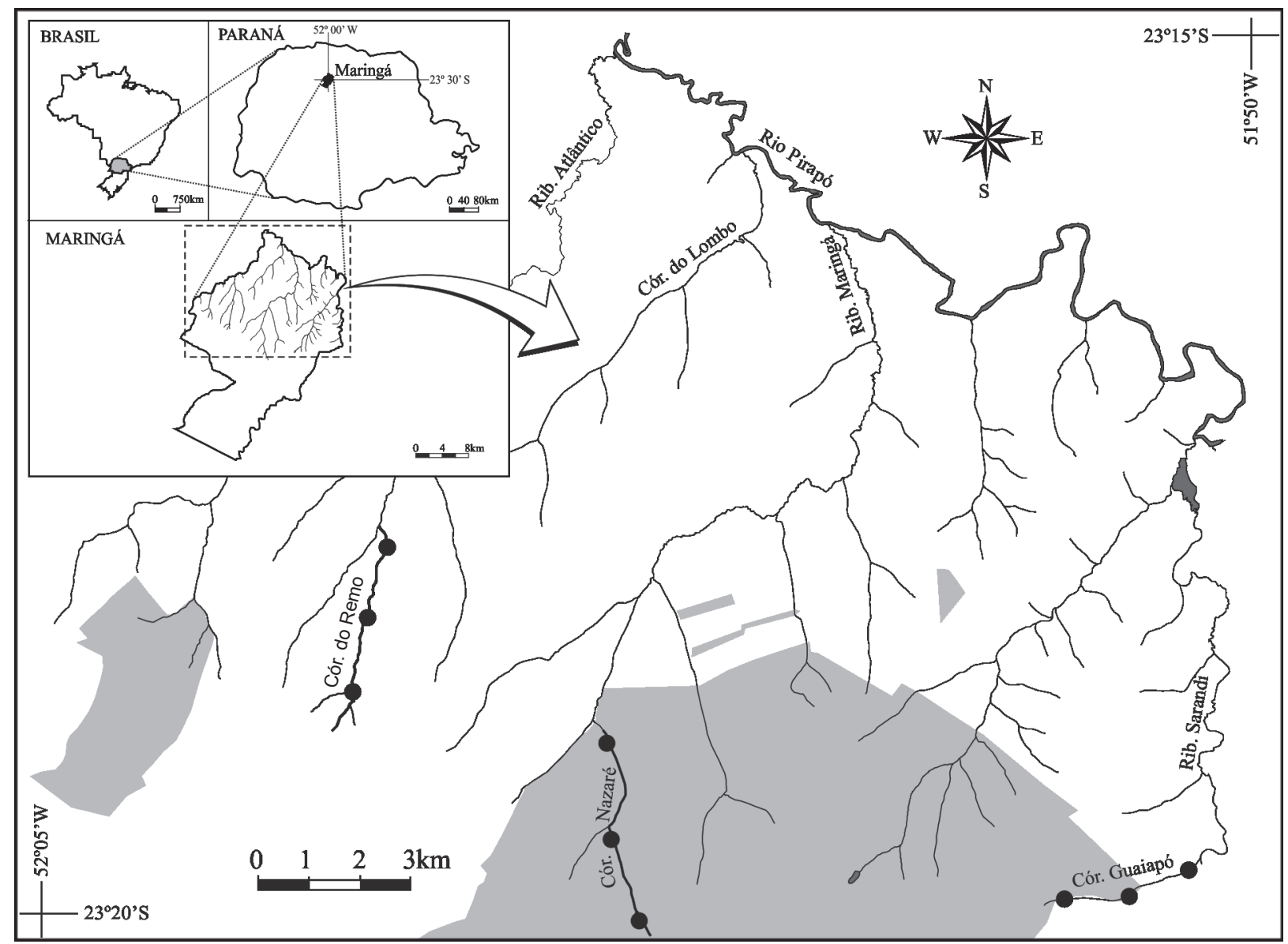

Figura 1. Localização dos Córregos Remo, Nazaré e Guaiapó no Município de Maringá, PR (cinza = área urbana; branco = área rural).

Figure 1. Location of Remo, Nazaré and Guaiapó streams in Maringá, Paraná State (gray = urban area; white = rural area).

estudo apenas as espécies abundantes e dominantes em pelo menos um local de coleta, em um ou nos três córregos foram selecionadas.

As fotomicrografias foram realizadas em microscópio Olympus BX40 com equipamento de captura de imagem Olympus DP71. A identificação dos táxons de diatomáceas perifíticas foi baseada em obras taxonômicas básicas (Patrick \& Reimer 1966, Krammer \& Lange-Bertalot 1986, 1988, 1991a, b, Rumrich et al. 2000, Lange-Bertalot 2001, Krammer 2002, Metzeltin \& Lange-Bertalot 1998, 2007, Metzeltin et al. 2005).

\section{Resultados e discussão}

A análise das amostras de diatomáceas perifíticas, coletadas nos Córregos Nazaré, Guaiapó e Remo, nos anos de 2007 e 2008, resultou na identificação de 151 táxons. Dentre estes, 80 foram encontrados no Córrego Nazaré, 96 no Guaiapó e 124 no Remo (C. Moresco, dados não publicados). Um total de 26 espécies foi considerado abundante e/ou dominante.

Sete espécies foram abundantes e/ou dominantes nos três córregos estudados, quais sejam: Eolimna minima (Grunow) Lange-Bertalot (dominante no Córrego Remo), Gomphonema lagenula Kützing (dominante no Córrego Guaiapó), Gomphonema pumilum (Grunow) Reichardt \& Lange-Bertalot e Nupela praecipua (Reichardt) Reichardt (dominantes no Córrego Nazaré), Geissleria aikenensis (Patrick) Torgan \& Oliveira, Nitzschia palea (Kützing) Smith e Sellaphora seminulum (Grunow) Mann (abundantes nos três córregos).

Treze espécies foram abundantes exclusivamente no Córrego Remo (Achnanthes rupestoides Hohn, Adlafia drouetiana (Patrick) Metzeltin \& Lange-Bertalot, Amphipleura lindheimeri Grunow, Amphora copulata (Kützing) Schoeman \& Archibald, Amphora normannii Rabenhorst, Aulacoseira ambigua (Grunow) Simonsen, 
Diploneis subovalis Cleve, Fragilaria rumpens (Kützing) Carlson, Luticola goeppertiana (Bleisch) Mann, Navicula lohmannii Lange-Bertalot \& Rumrich, Sellaphora sp., Stenopterobia schweickerdtii (Cholnoky) Brassac, Ludwig \& Torgan e Ulnaria ulna (Nitzsch) Compère). No Córrego Nazaré, apenas duas espécies abundantes foram exclusivas (Fallacia monoculata (Hustedt) Mann e Pinnularia latarea Krammer). No Córrego Guaiapó, quatro espécies foram exclusivamente abundantes (Cymbella kolbei Hustedt, Fragilaria rumpens var. familiaris (Kützing) Cleve-Euler, Gomphonema gracile Ehrenberg e Navicula symmetrica Patrick).

Família Aulacoseiraceae Aulacoseira ambigua (Grunow) Simonsen, Bacill. 2: 56,1979 . $\equiv$ Melosira crenulata (Ehrenberg) Kützing var. ambigua Grunow in Van Heurck, Syn. Diat. Belg., pl. 88, fig. 12-15, 1882.

Figuras 2-4

Frústulas cilíndricas, unidas em cadeias filamentosas retas por espinhos de ligação curtos, marginais; manto ornamentado por estrias oblíquas em relação ao eixo pervalvar; areolação conspícua. Diâmetro: 5,8-6,9 $\mu \mathrm{m}$, eixo pervalvar: $22,1-27,2 \mu \mathrm{m}, 14-16$ aréolas em $10 \mu \mathrm{m}$.

Ecologia: abundante na cabeceira do Córrego Remo, localizado na zona rural $(\mathrm{pH}: 6,96$, condutividade: $114,7 \mu \mathrm{S} \mathrm{cm}^{-1}, \mathrm{DBO}_{5}: 0,9 \mathrm{mg} \mathrm{O}_{2} \mathrm{~L}^{-1}$ ).

Material examinado: BRASIL. PARANÁ: Maringá, Córrego Remo, cabeceira, 04-VI-2007, C. Moresco s.n. (HUEM16541).

Família Fragilariaceae

Fragilaria rumpens (Kützing) Carlson var. rumpens, Wiss. Ergebn. Schw. Südp.-Exp.1901-1903, 4: 29, 1913. 三Synedra rumpens Kütz., Bacill., p. 69, pl.16, fig. 6 . 4, 5, 1844.

Figura 5

Valvas linear-lanceoladas, extremidades sutilmente rostradas, área axial linear, estreita, área central aproximadamente retangular, estrias paralelas, posição intercalada em relação às estrias da margem oposta. Eixo apical: 32-37 $\mu \mathrm{m}$, eixo transapical: 2,7-4 $\mu \mathrm{m}, 22$ estrias em $10 \mu \mathrm{m}$.

Comentário: a população analisada concorda com o material tipo da espécie analisado por Tuji \& Williams (2006), no que se refere a contorno valvar, forma das extremidades e variação métrica (25-63 $\mu \mathrm{m}$ de comprimento, 3-4 $\mu \mathrm{m}$ de lagura e 18-20 estrias em $10 \mu \mathrm{m})$.
Ecologia: abundante na cabeceira e no meio do Córrego Remo, que é rural ( $\mathrm{pH}: 6,64$ a 7,17, condutividade: 115,3 a $125,4 \mu \mathrm{S} \mathrm{cm}^{-1}, \mathrm{DBO}_{5}$ : 0,04 a 1,4 $\left.\mathrm{mg} \mathrm{O}_{2} \mathrm{~L}^{-1}\right)$.

Material examinado: BRASIL. PARANÁ: Maringá, Córrego Remo, meio, 25-VII-2007, C. Moresco s.n. (HUEM16527).

Fragilaria rumpens var. familiaris (Kützing) CleveEuler, Kungl. Sven. Vet.-Akad. Handl., ser.3, 11(2): 24, 1932. $\equiv$ Synedra familiaris Kützing, Bacillarien oder Diatomeen, p. 68, pl. 15, fig. 12, 1844.

Figuras 6-7

Valvas linear-lanceoladas; extremidades capitadas a subcapitadas; área axial estreita, linear, área central quadrada, de levemente intumescida a sem intumescimento, limitada por duas leves constrições em ambas as margens valvares; estrias paralelas, posição intercalada com as da margem oposta, interrompidas ou não na região mediana. Eixo apical: $51-85 \mu \mathrm{m}$, eixo transapical: 3,2-3,5 $\mu \mathrm{m}, 18$ estrias em $10 \mu \mathrm{m}$.

Comentário: F. rumpens var. familiaris apresenta semelhanças no padrão de estriação com $F$. gracilis Oestrup, sendo inclusive consideradas sinônimos por Krammer \& Lange-Bertalot (1991a). A análise do material tipo dos dois táxons permitiu constatar que $F$. gracilis apresenta extremidades menos capitadas que $F$. rumpens var. familiaris e ausência de constrição mediana na valva (Tuji 2007, Tuji \& Williams 2008).

Ecologia: abundante na cabeceira e no meio do Córrego Guaiapó, a qual é influenciada pela zona urbana (pH: 6,49 a 8,08, condutividade: 123,1 a $157,5 \mu \mathrm{S} \mathrm{cm}^{-1}$, $\mathrm{DBO}_{5}$ : 0 a $1,6 \mathrm{mg} \mathrm{O}_{2} \mathrm{~L}^{-1}$ ).

Material selecionado: BRASIL. PARANÁ: Maringá, Córrego Guaiapó, cabeceira, 07-VIII-2007, C. Moresco s.n. (HUEM16544).

Ulnaria ulna (Nitzsch) Compère in Jahn et al., Stud. Diat., p. 100, 2001. 三 Basiônimo: Bacillaria ulna Nitzsch, Neue Schr. Nat. Ges. Halle 3, (1): 99, pl. 5, 1817.

Figura 8

Valvas lineares a estreitamente linear-lanceoladas; extremidades rostradas a subcapitadas; área axial linear, estreita; área central expandida até às margens; estrias opostas, paralelas. Eixo apical: 44-153,4 $\mu \mathrm{m}$, eixo transapical: 7-9,8, $\mu \mathrm{m}$ 9-10 estrias em $10 \mu \mathrm{m}$.

Ecologia: abundante na cabeceira e no meio do Córrego Remo, que é localizado na zona rural (pH: 6,64 a 6,98 , condutividade: 115,3 a $125,9 \mu \mathrm{S} \mathrm{cm}^{-1}, \mathrm{DBO}_{5}$ : 0,04 a $\left.1 \mathrm{mg} \mathrm{O}_{2} \mathrm{~L}^{-1}\right)$. 

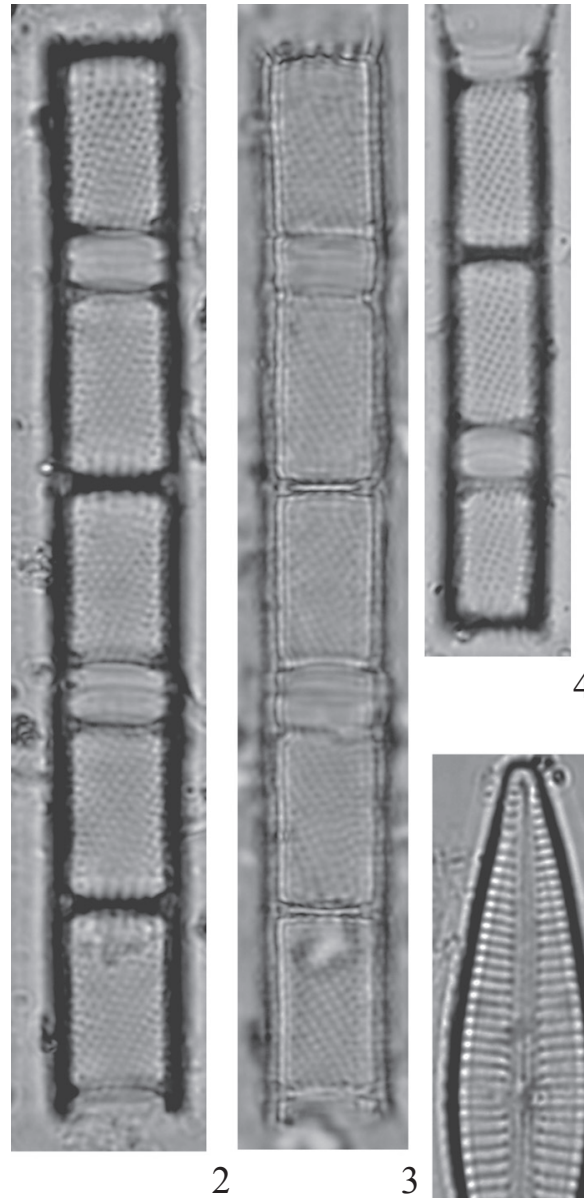

4
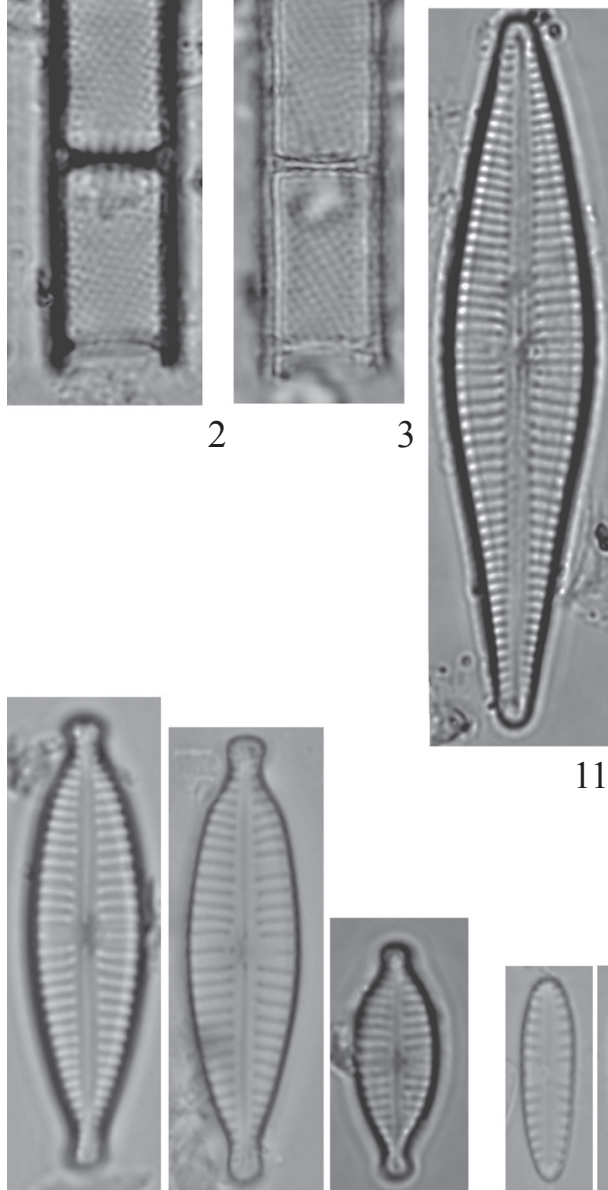

12
13

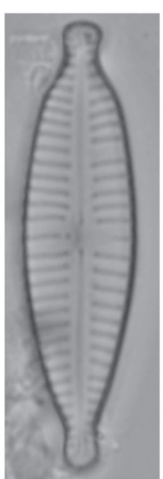

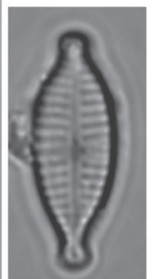

14

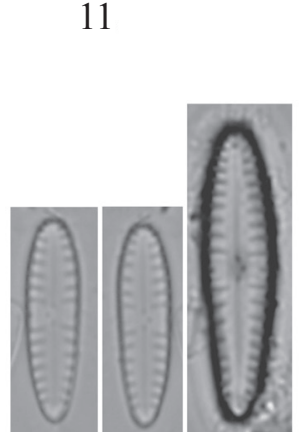

$\begin{array}{lll}15 & 16 & 17\end{array}$

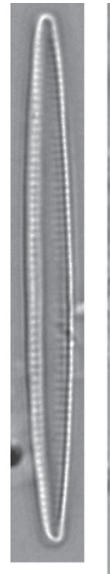

5
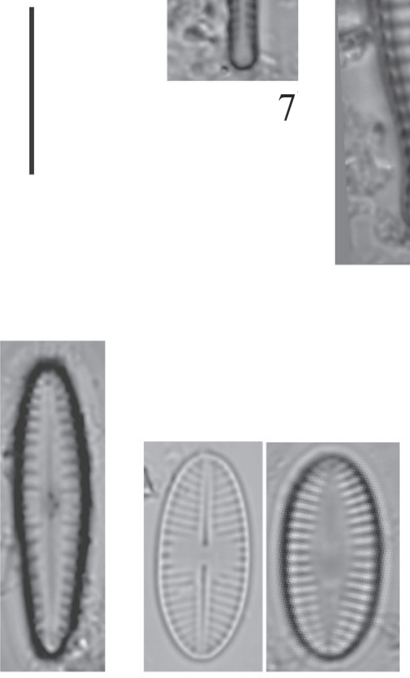

18
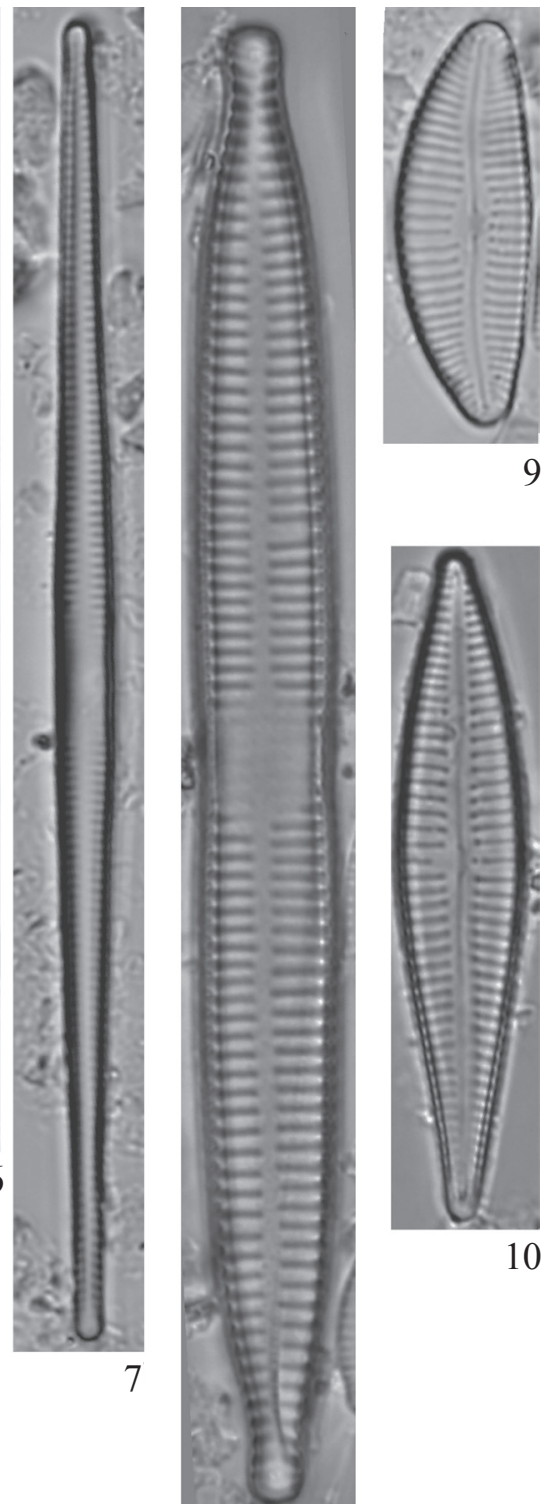

9

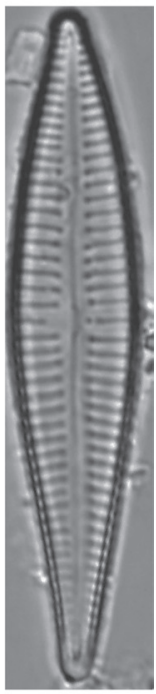

10

Figuras 2-21. 2-4. Aulacoseira ambigua. 5. Fragilaria rumpens var. rumpens. 6-7. Fragilaria rumpens var. familiaris. 8. Ulnaria ulna. 9. Cymbella kolbei. 10-11. Gomphonema gracile. 12-14. Gomphonema lagenula. 15-17. Gomphonema pumilum. 18-19. Achnanthes rupestoides. 20-21. Luticola goeppertiana. Barra $=10 \mu \mathrm{m}$.

Figures 2-21. 2-4. Aulacoseira ambigua. 5. Fragilaria rumpens var. rumpens. 6-7. Fragilaria rumpens var. familiaris. 8. Ulnaria ulna. 9. Cymbella kolbei. 10-11. Gomphonema gracile. 12-14. Gomphonema lagenula. 15-17. Gomphonema pumilum. 18-19. Achnanthes rupestoides. 20-21. Luticola goeppertiana. Bar $=10 \mu \mathrm{m}$. 
Material selecionado: BRASIL. ParanÁ: Maringá, Córrego Remo, cabeceira, 10-IV-2008, C. Moresco s.n. (HUEM16538).

Família Cymbellaceae

Cymbella kolbei Hustedt, Hydrobiol. 2(1): 46, figs 2026, 1949.

Figura 9

Valvas dorsiventrais, margem dorsal convexa, ventral moderadamente convexa; extremidades arredondadas a subrostradas; área axial arqueada, estreita; área central arredondada a lanceolada; rafe lateral, complexa, estrias transapicais radiadas, mais acentuadamente nas extremidades. Eixo apical: $22-25 \mu \mathrm{m}$, eixo transapical: 8-8,3 $\mu \mathrm{m}, 12$ estrias em $10 \mu \mathrm{m}$.

Comentário: C. kolbei $(=C$. hustedtii f. sinuata Compère) diferencia-se de $C$. affinis Kützing principalmente pela forma elíptica a elípticolanceolada da valva, pelas extremidades pouco rostradas a amplamente arredondadas. Enquanto que C. affinis apresenta valvas lanceoladas e extremidades rostradas (Metzeltin \& Lange-Bertalot 1998, Krammer 2002).

Ecologia: abundante na cabeceira do Córrego Guaiapó, que possui influência urbana $(\mathrm{pH}$ : 7,21, condutividade: $201 \mu \mathrm{S} \mathrm{cm}^{-1}$, $\mathrm{DBO}_{5}: 0,3 \mathrm{mg} \mathrm{O}_{2} \mathrm{~L}^{-1}$ ).

Material examinado: BRASIL. PARANÁ: Maringá, Córrego Guaiapó, cabeceira, 04-VI-2008, C. Moresco s.n. (HUEM16541).

Família Gomphonemataceae

Gomphonema gracile Ehrenberg, Infus., p. 217, pl. 8, fig. 3, 1838.

Figuras 10-11

Valvas levemente heteropolares, lanceoladas a rômbo-lanceoladas; ápices e bases atenuadoarredondados a subrostrados; área axial linear, estreita; área central limitada pelo encurtamento de uma estria mediana; estigma presente na base da estria mediana alongada; rafe filiforme; estrias paralelas a levemente radiadas, mais espaçadas entre si na região mediana da valva. Eixo apical: 31,4-45,6 $\mu \mathrm{m}$, eixo transapical: 5,2$8,3 \mu \mathrm{m}, 11-12$ estrias em $10 \mu \mathrm{m}$.

Ecologia: abundante no meio do Córrego Guaiapó, que é influenciado por áreas urbanas e rurais (pH: 8,08, condutividade: $157,5 \mu \mathrm{S} \mathrm{cm}^{-1}, \mathrm{DBO}_{5}$ : $0,23 \mathrm{mg} \mathrm{O}_{2} \mathrm{~L}^{-1}$ ).

Material examinado: BRASIL. PARANÁ: Maringá, Córrego Guaiapó, meio, 07-VIII-2007, C. Moresco s.n. (HUEM16545).
Gomphonema lagenula Kützing, Bacill., p. 85, pl. 30, fig. 60, 1844.

Figuras 12-14

Valvas levemente heteropolares, lanceoladas; ápices e bases capitadas a subcapitadas; área axial linear, estreita; área central limitada pelo encurtamento de uma estria mediana; estigma presente na estria mediana oposta; rafe filiforme, estrias paralelas a radiadas, levemente mais espaçadas na região mediana. Eixo apical: 13-27,3 $\mu \mathrm{m}$, eixo transapical: 5-6,4 $\mu \mathrm{m}, 12-16$ estrias em $10 \mu \mathrm{m}$.

Ecologia: abundante nos três córregos estudados, urbanos e rurais, o que indica sua tolerância a diferentes condições ambientais.

Material selecionado: BRASIL. PARANÁ: Maringá, Córrego Guaiapó, cabeceira, 10-V-2007, C. Moresco s.n. (HUEM16547); idem, Córrego Remo, meio, 24-IX-2007, C. Moresco s.n. (HUEM16530); idem, Córrego Nazaré, foz, 05-XII-2007, C. Moresco s.n. (HUEM16515).

Gomphonema pumilum (Grunow) Reichardt \& LangeBertalot, Nova Hedwigia 53(3-4): 528, pl. 6, fig. 4-11, 1991. $\equiv$ Gomphonema intricatum var. pumila CleveEuler, Kongl. Svensk. Vet.-Akad. Handl., ser. 3, 11(2): 99, fig. 252b, 1932.

Figuras 15-17

Valvas heteropolares, ligeiramente clavadas; ápices arredondados; bases atenuado-arredondadas; área axial lanceolada; formada pelo encurtamento de ambas as estrias medianas; estigma e nódulo central presentes; rafe filiforme; estrias espaçadas, levemente radiadas. Eixo apical: 12,2-28,6 $\mu \mathrm{m}$, eixo transapical: 2,9-4,4 $\mu \mathrm{m}$, 13 estrias em $10 \mu \mathrm{m}$.

Ecologia: abundante nos três córregos estudados e dominante na cabeceira do córrego urbano $(\mathrm{pH}: 6,64 \mathrm{a}$ 7,66, condutividade: 111,4 a $328 \mu \mathrm{S} \mathrm{cm}^{-1}, \mathrm{DBO}_{5}: 0,04$ a $3 \mathrm{mg} \mathrm{O}_{2} \mathrm{~L}^{-1}$ ).

Material selecionado: BRASIL. PARANÁ: Maringá, Córrego Guaiapó, cabeceira, 28-V-2008, C. Moresco s.n. (HUEM16559); idem, Córrego Remo, cabeceira, 03-XII-2007, C. Moresco s.n. (HUEM16532); idem, Córrego Nazaré, foz, 02-VII-2008, C. Moresco s.n. (HUEM16519).

Família Achnanthaceae

Achnanthes rupestoides Hohn, Trans. Amer. Micros. Soc. 80 (2): 154, pl. 1, fig. 3-4, 1961.

Figuras 18-19

Valvas elípticas; extremidades arredondadas; valva com rafe: área axial linear estreita, área central estreita, 
pelo leve encurtamento das estrias; rafe filiforme, estrias radiadas; valva sem rafe: área axial lanceolada, estrias radiadas em direção à extremidade. Eixo apical: 12$13,9 \mu \mathrm{m}$, eixo transapical: 5-6,5 $\mu \mathrm{m}, 17-18$ estrias em $10 \mu \mathrm{m}$.

Ecologia: abundante na cabeceira e no meio do Córrego Remo, rural (pH: 6,39 a 7,5, condutividade: 98,3 a 125,9 $\mu \mathrm{S} \mathrm{cm}^{-1}, \mathrm{DBO}_{5}$ : 0,04 a 2,5 $\mathrm{mg} \mathrm{O}_{2} \mathrm{~L}^{-1}$ ).

Material selecionado: BRASIL. PARANÁ: Maringá, Córrego Remo, cabeceira, 14-II-2008, C. Moresco s.n. (HUEM16535); idem, meio, 04-VI-2008, C. Moresco s.n. (HUEM16542).

\section{Família Diadesmidaceae}

Luticola goeppertiana (Bleisch) Mann in Round, Crawford \& Mann, Diatoms, p. 670, 1990. इ Navicula mutica Kützing var. goeppertiana Bleisch in Rabenhorst, Alg. Eur., n. 1183, 1861.

Figuras 20-21

Valvas amplamente lanceoladas; extremidades subrostradas; área axial linear; área central expandida transversalmente, circundada por estrias encurtadas; presença de estigma; rafe filiforme, com extremidades proximais curvadas em direção contrária ao estigma; estrias radiadas; aréolas conspícuas. Eixo apical: 15-32,2 $\mu \mathrm{m}$, eixo transapical: 5,8-8,3 $\mu \mathrm{m}, 22-24$ estrias em $10 \mu \mathrm{m}$.

Ecologia: abundante na cabeceira e no meio do Córrego Remo, o qual é rural (pH: 6,64 a 7,17, condutividade: 115,3 a $125,4 \mu \mathrm{S} \mathrm{cm}^{-1}, \mathrm{DBO}_{5}$ : 0,04 a $1,4 \mathrm{mg} \mathrm{O}_{2} \mathrm{~L}^{-1}$ ).

Material selecionado: BRASIL. PARANÁ: Maringá, Córrego Remo, cabeceira, 24-IX-2007, C. Moresco s.n. (HUEM16529); idem, meio, 04-VI-2008, C. Moresco s.n. (HUEM16542).

Família Amphipleuraceae

Amphipleura lindheimeri Grunow, Verh. Zool.-Bot., Ges. Wien. 12: 469, pl. 11, fig. 11 a-b, 1862.

Figura 22

Valvas lanceoladas, extremidades rostrado arredondadas, rafe curta, localizada em costela silicosa próximo as extremidades valvares, com comprimento de aproximadamente $1 / 3$ do tamanho da valva; estrias delicadas de difícil visualização ao microscópio óptico. Eixo apical: 120-184,9 $\mu \mathrm{m}$, eixo transapical: 20-24 $\mu \mathrm{m}$.

Ecologia: abundante na cabeceira do Córrego Remo, que possui curso na zona rural ( $\mathrm{pH}: 6,75$, condutividade: $\left.125,9 \mu \mathrm{S} \mathrm{cm}^{-1}, \mathrm{DBO}_{5}: 1,5 \mathrm{mg} \mathrm{O}_{2} \mathrm{~L}^{-1}\right)$.
Material examinado: BRASIL. PARANÁ: Maringá, Córrego Remo, cabeceira, 10-IV-2008, C. Moresco s.n. (HUEM16538).

\section{Família Sellaphoraceae}

Fallacia monoculata (Hustedt) Mann in Round, Crawford \& Mann, Diatoms, p. 668, 1990. 三Navicula monoculata Hustedt, Arch. Hydrobiol. 40: 921, 1945.

Figuras 23-25

Valvas elípticas a lanceoladas; extremidades arredondadas; área axial linear, estreita; área central reduzida; rafe levemente arqueada; nódulos distais refringentes; estrias medianas mais espaçadas entre si, radiadas em toda a valva, interrompidas por uma linha longitudinal próxima a área axial. Eixo apical: 10,4-15,5 $\mu \mathrm{m}$, eixo transapical: 4-5,5 $\mu \mathrm{m}, 22$ estrias em $10 \mu \mathrm{m}$.

Ecologia: abundante na foz do Córrego Nazaré, o qual está localizado inteiramente na zona urbana $(\mathrm{pH}$ : 6,89 a 7,05, condutividade: 229 a $354 \mu \mathrm{S} \mathrm{cm}^{-1}, \mathrm{DBO}_{5}$ : 0,9 a $\left.1,2 \mathrm{mg} \mathrm{O}_{2} \mathrm{~L}^{-1}\right)$.

Material selecionado: BRASIL. PARANÁ: Maringá, Córrego Nazaré, foz, 02-VII-2008, C. Moresco s.n. (HUEM16519).

Sellaphora seminulum (Grunow) Mann, Br. Phycol. J. 24: 2, 1989. इ Navicula seminulum Grunow, Verh. Zool.-Bot. Ges. Wien. 10: 552, pl. 4, fig. 3, 1860.

Figuras 26-32

Valvas elíptico-lanceoladas a elípticas; extremidades arredondadas; área axial linear, estreita; área central pouco expandida, limitada pelo encurtamento irregular das estrias medianas; rafe filiforme, reta; estrias radiadas, mais espaçadas entre si na região mediana. Eixo apical: 7-16,5 $\mu \mathrm{m}$, eixo transapical: 3,5-5 $\mu \mathrm{m}, 20-24$ estrias em $10 \mu \mathrm{m}$.

Em MEV, a espécie apresenta estrias bisseriadas compostas por aréolas arredondadas, extremidades distais da rafe curvadas para o mesmo lado e extremidades proximais pouco fletidas (Fig. 32).

Ecologia: abundante nos três córregos. ( $\mathrm{pH}: 6,39$ a 8,24, condutividade: 98,3 a $354 \mu \mathrm{S} \mathrm{cm}^{-1}, \mathrm{DBO}_{5}: 0,04$ a $5,5 \mathrm{mg} \mathrm{O}_{2} \mathrm{~L}^{-1}$ ).

Material selecionado: BRASIL. PARANÁ: Maringá, Córrego Remo, meio, 14-II-2008, C. Moresco s.n. (HUEM16536); idem, Córrego Nazaré, cabeceira, 27-V-2008, C. Moresco s.n. (HUEM16523); idem, meio, 01-IV-2008, C. Moresco s.n. (HUEM16521). 

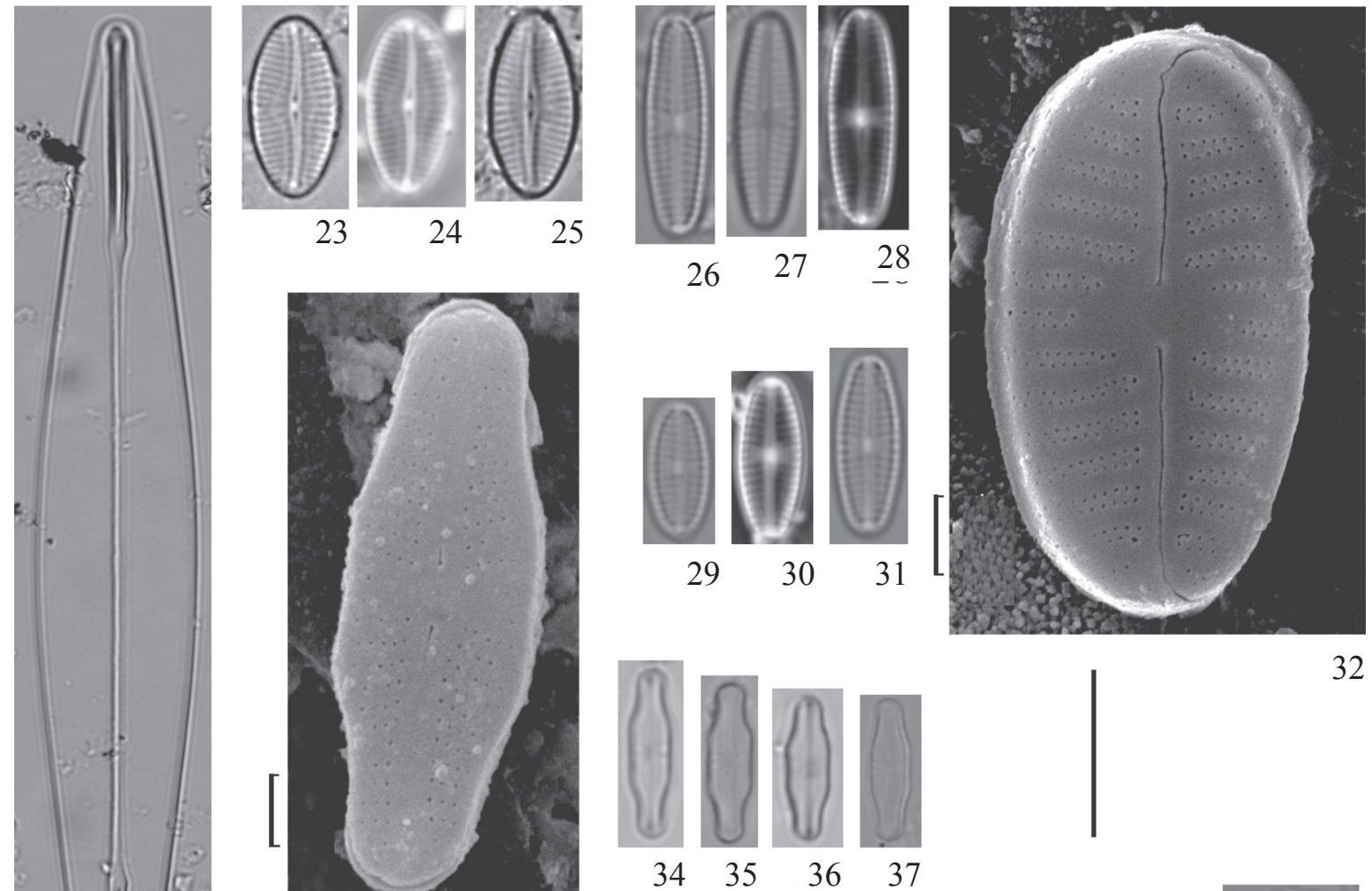

32

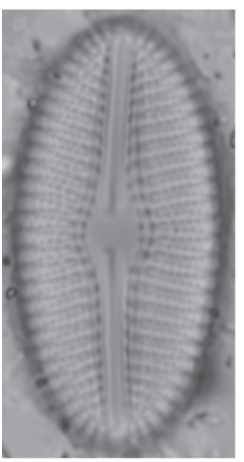

38

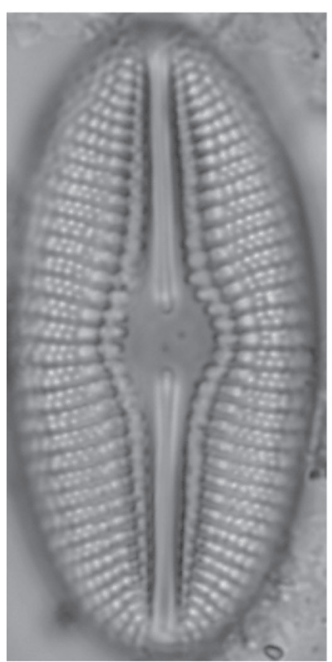

39

\section{3}

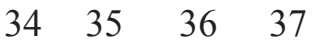

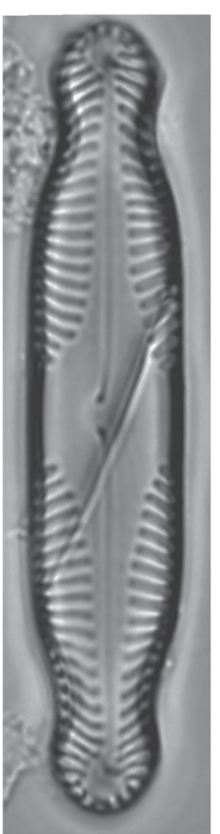

40

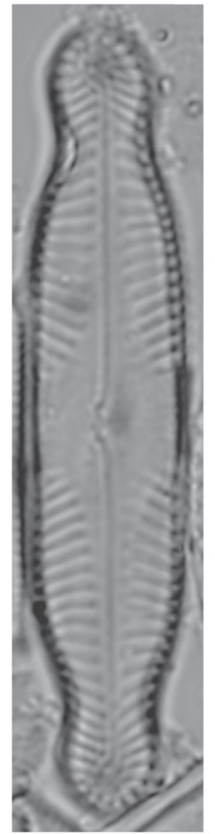

41

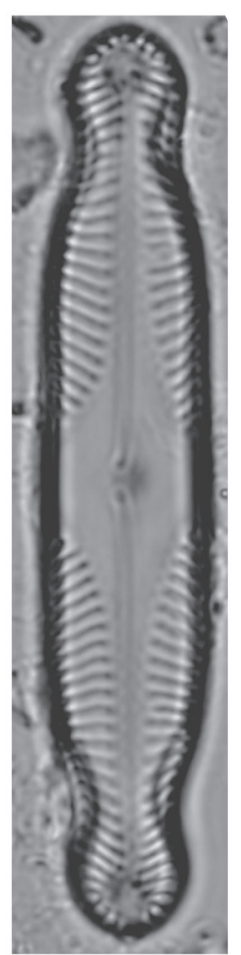

42

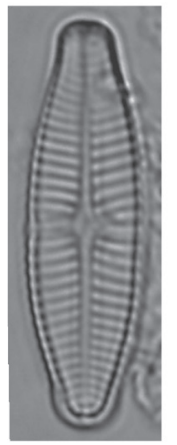

.43

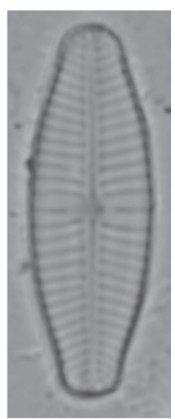

44

Figuras 22-44. 22. Amphipleura lindheimeri. 23-25. Fallacia monoculata. 26-32. Sellaphora seminulum. 33-37. Sellaphora sp. 38-39. Diploneis subovalis. 40-42. Pinnularia latarea. 43-44. Geissleria aikenensis. Barra $=10 \mu \mathrm{m}(22-31 / 34-44) ;=1 \mu \mathrm{m}$ (32-33).

Figures 22-44. 22. Amphipleura lindheimeri. 23-25. Fallacia monoculata. 26-32. Sellaphora seminulum. 33-37. Sellaphora sp. 38-39. Diploneis subovalis. 40-42. Pinnularia latarea. 43-44. Geissleria aikenensis. Bar $=10 \mu \mathrm{m},(22-31 / 34-44) ;=1 \mu \mathrm{m}$ (32-33). 


\section{Sellaphora sp.}

Figuras 33-37

Valvas lineares, com leve constrição mediana; extremidades levemente subcapitadas; área axial linear, estreita, circular, formada pelo encurtamento das estrias da região mediana; rafe filiforme, reta; estrias mais espaçadas na região mediana. Eixo apical: 8,2-9 $\mu \mathrm{m}$, eixo transapical: $2,6-3 \mu \mathrm{m}$.

Em MEV, a espécie apresenta superfície valvar plana, com área central delimitada pelo encurtamento irregular de 2-3 estrias. Estrias unisseriadas, radiadas a paralelas próximas as extremidades, compostas por aréolas arredondadas. Rafe reta com extremidades proximais expandidas e levemente fletidas para um dos lados, extremidades distais curvadas (Fig. 33).

Comentário: os exemplares encontrados concordam com a descrição de Sellaphora dada por Round et al. (1990). Segundo os autores, o gênero caracterizase por apresentar superfície valvar plana curvada abrupta ou levemente em direção ao manto, estrias unisseriadas formadas por aréolas arredondadas, rafe com extremidades proximais e distais fletidas.

Ecologia: abundante na foz do Córrego rural $(\mathrm{pH}$ : 6,68 a 7,08, condutividade: 108,9 a $116,9 \mu \mathrm{S} \mathrm{cm}^{-1}, \mathrm{DBO}_{5}$ : 0,9 a $\left.1,2 \mathrm{mg} \mathrm{O}_{2} \mathrm{~L}^{-1}\right)$.

Material selecionado: BRASIL. PARANÁ: Maringá, Córrego Remo, foz, 04-VI-2008, C. Moresco s.n. (HUEM16543).

Família Diploneidaceae

Diploneis subovalis Cleve, Syn. Navic. Dist. Kong., p. 96, pl. 1, fig. 7, 1894.

Figuras 38-39

Valvas elípticas; extremidades arredondadas; área axial linear-lanceolada, estreita; área central arredondada; canal longitudinal largo, mais distanciado na região central, rafe filiforme; costelas transapicais robustas, radiadas; entre um par de costelas um sistema de fileira dupla de aréolas em quincunce. Eixo apical; 20,3-31,1 $\mu \mathrm{m}$, eixo transapical: 11-18,7 $\mu \mathrm{m}, 9-11$ estrias em $10 \mu \mathrm{m}$.

Ecologia: abundante na cabeceira e no meio do córrego rural (pH: 6,64 a 7,22, condutividade: 111,4 a $125,9 \mu \mathrm{S} \mathrm{cm}^{-1}, \mathrm{DBO}_{5}$ : 0,04 a 1,5 mg O $\left.\mathrm{L}^{-1}\right)$.

Material selecionado: BRASIL. PARANÁ: Maringá, Córrego Remo, cabeceira, 10-IV-2008, C. Moresco s.n. (HUEM16538); idem, meio, 25-VII-2007, C. Moresco s.n. (HUEM16527).
Família Pinnulariaceae

Pinnularia latarea Krammer in Lange-Bertalot, Diatoms of Europe 1: 110, 224, pl. 84, fig. 13-15, 2000.

Figuras 40-42

Valvas lineares a linear-lanceoladas, delicadamente onduladas, extremidades capitadas; área axial distinta, estreita; área central expandida; rafe filiforme, estrias radiadas no centro da valva e convergentes nas extremidades. Eixo apical: 40-48 $\mu \mathrm{m}$, eixo transapical: 7,7-9 $\mu \mathrm{m}, 10-11$ estrias em $10 \mu \mathrm{m}$.

Comentário: P. subanglica Krammer e P. rumrichae Krammer diferenciam-se de $P$. latarea por apresentarem valvas mais estreitas (7-8 e 6,8-7,5 $\mu \mathrm{m}$ de largura, respectivamente), maior razão comprimento/largura (5,8 e 5,6-6,8, respectivamente, contra 4,6) e lados da valva retos a sutilmente convexos (Krammer 2000).

Ecologia: abundante na foz do Córrego Nazaré, que possui seu curso inteiramente no meio urbano ( $\mathrm{pH}: 7,05$, condutividade: $229 \mu \mathrm{S} \mathrm{cm}^{-1}$, $\mathrm{DBO}_{5}: 1,2 \mathrm{mg} \mathrm{O}_{2} \mathrm{~L}^{-1}$ ).

Material examinado: BRASIL. PARANÁ: Maringá, Córrego Nazaré, 02-VII-2008, C. Moresco s.n. (HUEM16519).

Família Naviculaceae

Geissleria aikenensis (Patrick) Torgan \& Oliveira, Proc. $16^{\text {th }}$ Intern. Diatom Symp., p. 115-125, fig. 2-19, 2000. $\equiv$ Navicula aikenensis Patrick, Proc. Akad. Nat. Sc. Phil., 3: 92, fig. 7-6, 1959.

Figuras 43-44

Valvas lanceoladas; extremidades amplamente rostradas; área axial linear, estreita; área central circular, reduzida; estigma central; rafe filiforme, reta; estrias radiadas em toda a extensão valvar, estrias medianas mais espaçadas. Eixo apical: 15,5-24 $\mu \mathrm{m}$, eixo transapical: 5,5-7 $\mu \mathrm{m}, 15-16$ estrias em $10 \mu \mathrm{m}$.

Ecologia: abundante nos três córregos, urbanos e/ou rurais.

Material selecionado: BRASIL. PARANÁ: Maringá, Córrego Guaiapó, meio, 07-VIII-2007, C. Moresco s.n. (HUEM16545); idem, Córrego Remo, cabeceira, 14-II-2008, C. Moresco s.n. (HUEM16535); idem, Córrego Nazaré, foz, 02-VII-2008, C. Moresco s.n. (HUEM16519).

Navicula lohmannii Lange-Bertalot \& Rumrich in U. Rumrich, Lange-Bertalot \& M. Rumrich, Iconogr. Diatomol. 9: 163, pl. 36, fig. 1-8, pl. 37, fig. 1-4, 2000. Figuras 45-46

Valvas lanceoladas; extremidades atenuadoarredondadas; área axial linear, estreita; área central 
arredondada, ampla, limitada pelo encurtamento das estrias medianas; rafe complexa; estrias radiadas na região mediana e quase paralelas a convergentes em direção às extremidades. Eixo apical: 40,5-91 $\mu \mathrm{m}$, eixo transapical: 6,2-10 $\mu \mathrm{m}, 11-12$ estrias em $10 \mu \mathrm{m}$.

Ecologia: abundante na cabeceira e no meio no córrego rural ( $\mathrm{pH}: 6,39$ a 7,22, condutividade: 98,3 a $125,9 \mu \mathrm{S} \mathrm{cm}^{-1}, \mathrm{DBO}_{5}: 0,04$ a $2,5 \mathrm{mg} \mathrm{O}_{2} \mathrm{~L}^{-1}$ ).

Material selecionado: BRASIL. PARANÁ: Maringá, Córrego Remo, cabeceira, 03-XII-2007, C. Moresco s.n. (HUEM16532); idem, meio, 25-VII-2007, C. Moresco s.n. (HUEM16527).

Navicula symmetrica Patrick, Bol. Mus. Nac., nov. ser., bot. 2:5; fig. 6, 1944.

Figura 47

Valvas elípticas; extremidades agudo-arredondadas; área axial linear, estreita; área central arredondada, assimétrica, limitada pelo encurtamento das estrias medianas; rafe filiforme, reta, extremidades proximais curvadas para o mesmo lado; estrias radiadas em toda a superfície valvar. Eixo apical: $23-29 \mu \mathrm{m}$, eixo transapical: 6,1-7 $\mu \mathrm{m}, 14-16$ estrias em $10 \mu \mathrm{m}$.

Comentário: espécies semelhantes a $N$. symmetrica, como N. schroeteri Meister e N. escambia (Patrick) Metzeltin \& Lange-Bertalot diferenciam-se pela forma e dimensões valvares, área central e densidade de estrias. N. schroeteri apresenta valvas lanceoladas a linear-lanceoladas, extremidades cuneadas a agudoarredondadas, área central retangular, 44-77 $\mu \mathrm{m}$ de comprimento, 9-12,6 $\mu \mathrm{m}$ de largura e 11-12 estrias em $10 \mu \mathrm{m}$. Já $N$. escambia possui valvas elípticas com extremidades amplamente arredondadas, área central elíptica, 33-50 $\mu \mathrm{m}$ de comprimento, 7-9 $\mu \mathrm{m}$ de largura e 12-14 estrias em $10 \mu \mathrm{m}$ (Patrick \& Reimer 1966, Morales 2001, Metzeltin \& Lange-Bertalot 2007).

Ecologia: abundante na cabeceira eno meio do Córrego Guaiapó, o qual sofre influência tanto do meio urbano, quanto do meio rural ( $\mathrm{pH}: 6,49$ a 8,08 , condutividade: 123,1 a $200 \mu \mathrm{S} \mathrm{cm}^{-1}, \mathrm{DBO}_{5}$ : 0 a 1,3 $\mathrm{mg} \mathrm{O}_{2} \mathrm{~L}^{-1}$ ).

Material selecionado: BRASIL. PARANÁ: Maringá, Córrego Guaiapó, meio, 04-IV-2008, C. Moresco s.n. (HUEM16557).

Nupela praecipua (Reichardt) Reichardt in Rumrich et al., Iconogr. Diatomol. 9: 196, 2000. $\equiv$ Achnanthes praecipua Reichardt, Proc. $9^{\text {th }}$ Inter. Diat. Symp., p. 391, fig. 1-24, 1988. Figuras 48-55

Valvas lanceoladas a elíptico-lanceoladas; extremidades atenuado-arredondadas à subrostradas; valva com rafe: área axial linear, estreita; área central reduzida; rafe filiforme; estrias inconspícuas; valva sem rafe: área axial lanceolada, às vezes granulosa; área central indistinta; estrias inconspícuas. Eixo apical: 14-17,5 $\mu \mathrm{m}$, eixo transapical: 4,1-5 $\mu \mathrm{m}$.

Em MEV, a face interna da valva rafídea apresenta estrias unisseriadas, levemente radiadas, formadas por aréolas arredondadas, área central ampla, arredondadas e uma pequena helictoglossa ao término da rafe. Externamente, a valva arrafídea possui área axial ornamentada por espessamentos silíceos, estrias delicadas, levemente radiadas.

Ecologia: abundante nos três córregos (urbanos e/ou rurais), indicando a tolerância por condições ambientais distintas. Foi dominante na cabeceira do córrego localizado na zona urbana, em dois períodos de coleta (pH: 6,39 a 7,98, condutividade: 98,3 a $354 \mu \mathrm{S}$ $\mathrm{cm}^{-1}, \mathrm{DBO}_{5}$ : 0,04 a $\left.3 \mathrm{mg} \mathrm{O}_{2} \mathrm{~L}^{-1}\right)$.

Material selecionado: BRASIL. PARANÁ: Maringá, Córrego Guaiapó, cabeceira, 07-VIII-2007, C. Moresco s.n. (HUEM16544); idem, Córrego Remo, meio, 03-XII-2007, C. Moresco s.n. (HUEM16533); idem, Córrego Nazaré, cabeceira, 02-VII-2008, C. Moresco s.n. (HUEM16517).

Adlafia drouetiana (Patrick) Metzeltin \& Lange-Bertalot, Iconogr. Diatomol. 5: 21, pl. 86, fig. 14-19, pl. 186, fig. 6,1998 . $\equiv$ Navicula drouetiana Patrick, Bol. Mus. Nac. Rio de Janeiro 2: 4, fig. 4, 1944.

Figuras 56-58

Valvas elípticas a linear-lanceoladas, com ondulações tênues; extremidades rostradas, área axial estreita, linear; área central formada pelo encurtamento das estrias; rafe filiforme; reta; estrias radiadas, levemente mais espaçadas entre si na região mediana. Eixo apical: 12-21,1 $\mu \mathrm{m}$, eixo transapical: 3,5-5,2 $\mu \mathrm{m}, 26$ estrias em $10 \mu \mathrm{m}$.

Ecologia: abundante no meio e na foz do córrego localizado inteiramente na zona rural ( $\mathrm{pH}$ : 6,63 a 7,76, condutividade: 103,2 a $125,4 \mu \mathrm{S} \mathrm{cm}^{-1}, \mathrm{DBO}_{5}: 0,04$ a 2,2 $\mathrm{mg} \mathrm{O}_{2} \mathrm{~L}^{-1}$ ).

Material selecionado: BRASIL. PARANÁ: Maringá, Córrego Remo, foz, 10-IV-2008, C. Moresco s.n. (HUEM16540).

Eolimna minima (Grunow) Lange-Bertalot in Moser, Lange-Bertalot \& Metzeltin, Biblioth. Diatomol. 38: 153, pl. 24, fig. 10-15, 1998. = Navicula minima Grunow in Van Heurck, Syn. Diat. Belg., pl. 14, fig. 15, 1880. Figuras 59-66

Valvas elípticas a lanceoladas; extremidades arredondadas; área axial linear, estreita; área central 

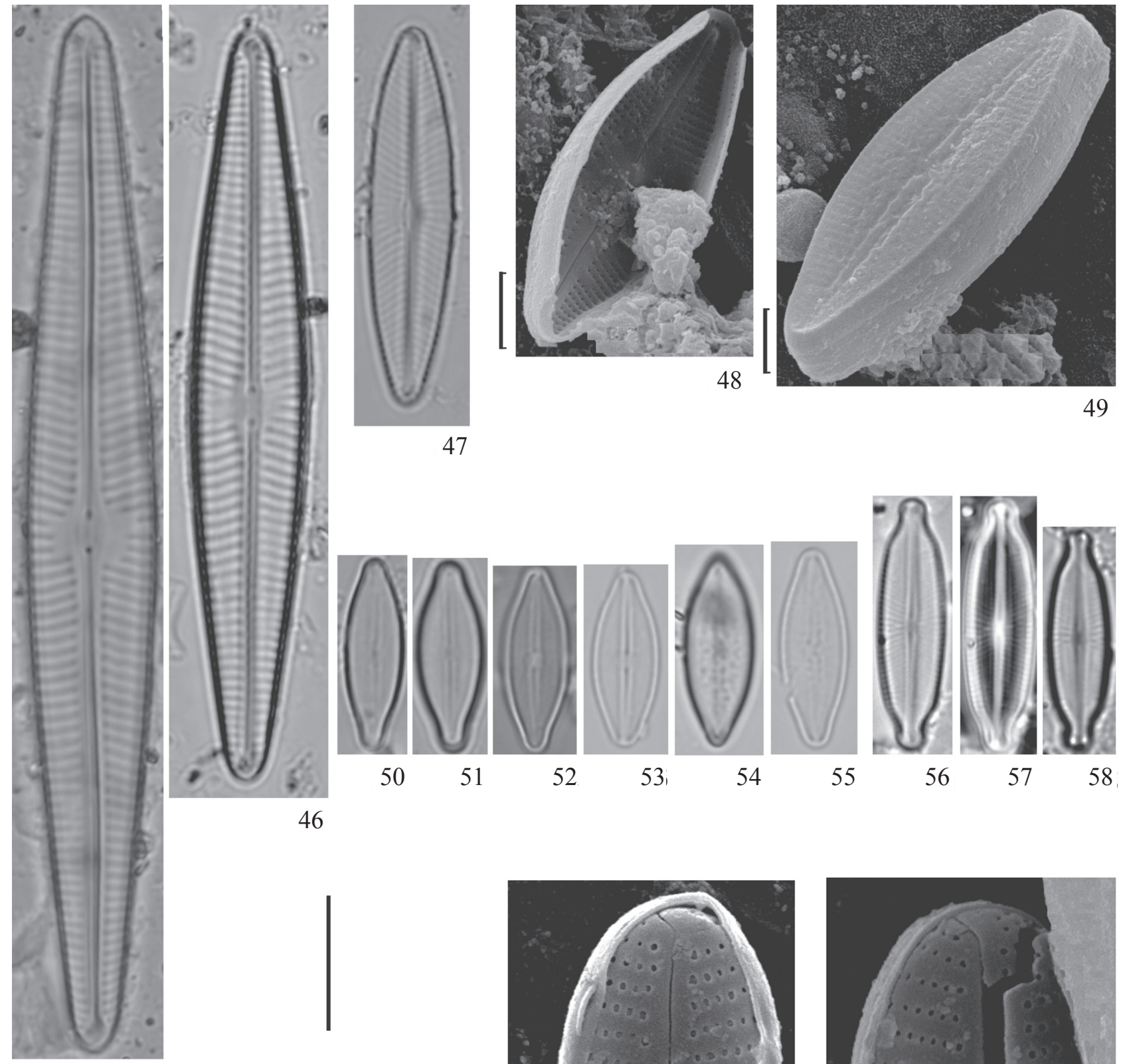

47
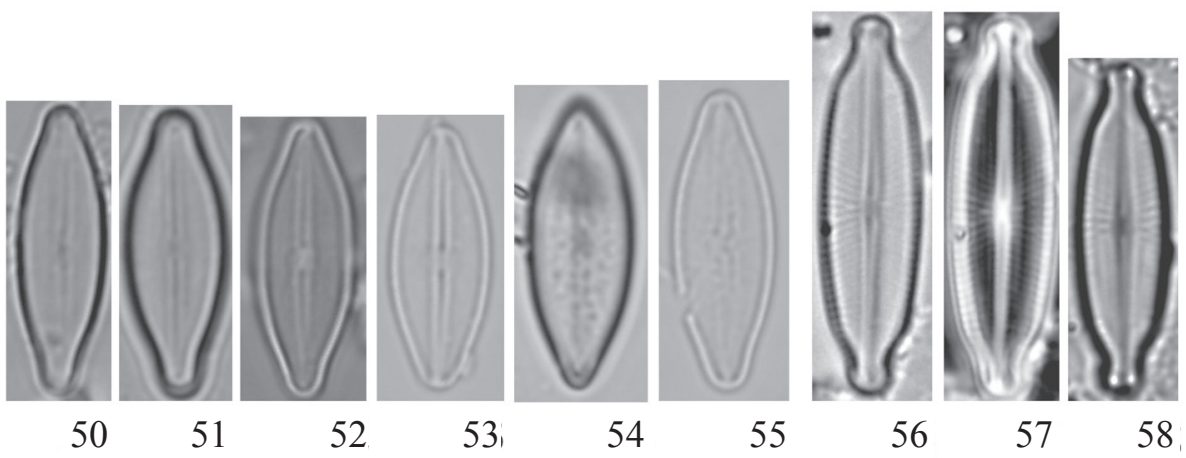

45
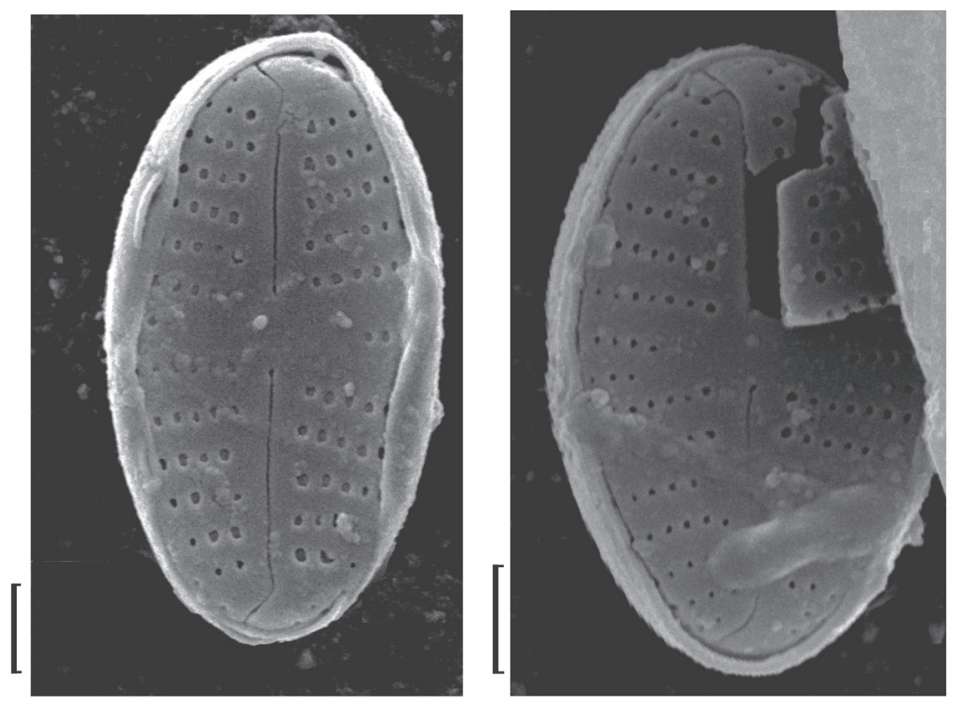

65

Figuras 45-66. 45-46. Navicula lohmanii. 47. Navicula symmetrica. 48-55. Nupela praecipua. 56-58. Adlafia drouetiana. 5966. Eolimna minima. Barra $=10 \mu \mathrm{m}(45-47 / 50-64) ;=2 \mu \mathrm{m}(48,49) ;=1 \mu \mathrm{m}(65,66)$.

Figures 45-66. 45-46. Navicula lohmanii. 47. Navicula symmetrica. 48-55. Nupela praecipua. 56-58. Adlafia drouetiana. 5966. Eolimna minima. $\mathrm{Bar}=10 \mu \mathrm{m}(45-47 / 50-64) ;=2 \mu \mathrm{m}(48,49) ;=1 \mu \mathrm{m}(65,66)$. 
pouco expandida, limitada pelo encurtamento irregular das estrias medianas; rafe filiforme, reta; estrias radiadas, mais espaçadas entre si na região mediana. Eixo apical: 5,2-10,4 $\mu \mathrm{m}$, eixo transapical: 3,3-4,2 $\mu \mathrm{m}, 27$ estrias em $10 \mu \mathrm{m}$.

Em MEV, as frústulas apresentam superfície valvar plana, estrias unisseriadas, radiadas, compostas por aréolas arredondadas, rafe reta com extremidades proximais levemente fletidas e distais fortemente curvadas.

Ecologia: abundante nos três córregos estudados sejam eles urbanos ou rurais, corroborando a sua tolerância a diferentes condições ambientais. Foi dominante no meio e na foz do Córrego Remo, localizado na zona rural (pH: 6,39 a 8,24, condutividade: 98,3 a $354 \mu \mathrm{S} \mathrm{cm}^{-1}, \mathrm{DBO}_{5}$ : 0 a $\left.5,5 \mathrm{mg} \mathrm{O}_{2} \mathrm{~L}^{-1}\right)$.

Material selecionado: BRASIL. PARANÁ: Maringá, Córrego Guaiapó, meio, 12-XII-2007, C. Moresco s.n. (HUEM16551); idem, Córrego Remo, foz, 04-VI-2008, C. Moresco s.n. (HUEM16543); idem, Córrego Nazaré; meio, 02-VII-2008, C. Moresco s.n. (HUEM16518).

Família Catenulaceae Amphora copulata (Kützing) Schoeman \& Archibald, S. Afr. J. Bot. 52: 5, p. 429, fig. 11-53, 1986. 三Frustulia copulata Kützing, Alg. Germ., Decas I-XVI, exciccatae, text s.p., 39 p. 1833-1836.

Figuras 67-69

Valvas semi-elíptico, margem dorsal convexa, margem ventral côncava, levemente intumescida na região mediana; extremidades atenuado-arredondadas; área axial arqueada, estreita; área central expandida ventralmente atingindo a margem ventral; rafe arqueada, extremidades proximais curvadas dorsalmente; estrias dorsais radiadas interrompidas na região mediana, estrias ventrais mais fortemente radiadas. Eixo apical: 20,3$35 \mu \mathrm{m}$, eixo transapical: 4,1-7 $\mu \mathrm{m}, 13-14$ estrias dorsais em $10 \mu \mathrm{m}, 13-15$ estrias ventrais em $10 \mu \mathrm{m}$.

Ecologia: abundante na cabeceira e no meio do córrego rural (pH: 6,64 a 6,96, condutividade: 114,7 a $125,9 \mu \mathrm{S} \mathrm{cm}^{-1}, \mathrm{DBO}_{5}: 0,04$ a $\left.1,5 \mathrm{mg} \mathrm{O}_{2} \mathrm{~L}^{-1}\right)$.

Material selecionado: BRASIL. PARANÁ: Maringá, Córrego Remo, cabeceira, 04-VI-2008, C. Moresco s.n. (HUEM16541).

Amphora normanii Rabenhorst, Fl. Europea Alg., 1, p. 88. 1864.

Figuras 70-72

Valvas semilanceoladas, margem dorsal convexa, levemente ondulada e margem ventral levemente convexa; extremidades capitadas; rafe filiforme; nódulo central proeminente; extremidades distais e proximais direcionadas dorsalmente, estrias transapicais dorsais pontuadas, levemente radiadas, mais espaçadas na região central; estrias ventrais encurtadas e paralelas. Eixo apical: 26-34,9 $\mu \mathrm{m}$, eixo transpical: 4,9-6,2 $\mu \mathrm{m}$, 17 estrias dorsais em $10 \mu \mathrm{m}$.

Ecologia: abundante na cabeceira do Córrego Remo, que é rural (pH: 6,75 a 6,96, condutividade: 114,7 a $125,9 \mu \mathrm{S} \mathrm{cm}^{-1}, \mathrm{DBO}_{5}: 0,9$ a $1,5 \mathrm{mg} \mathrm{O}_{2} \mathrm{~L}^{-1}$ ).

Material selecionado: BRASIL. PARANÁ: Maringá, Córrego Remo, cabeceira, 10-IV-2008, C. Moresco s.n. (HUEM16538).

Família: Bacillariaceae

Nitzschia palea (Kützing) Smith, Syn. British. Diat. 2: 89, 1856. $\equiv$ Synedra palea Kützing, Bacill., p. 63, fig. 27, 1844.

Figuras 73-75

Valvas linear-lanceoladas; extremidades rostradoarredondadas a subcapitadas; fíbulas marginais não eqüidistantes entre si; estrias inconspícuas. Eixo apical: 18-47,5 $\mu \mathrm{m}$, eixo transapical: $3,5-4,2 \mu \mathrm{m}, 11-13$ fíbulas em $10 \mu \mathrm{m}$.

Ecologia: abundante nos três córregos, urbanos e rurais.

Material selecionado: BRASIL. PARANÁ: Maringá, Córrego Guaiapó, cabeceira, 12-XII-2007, C. Moresco s.n. (HUEM16550); idem, Córrego Remo, meio, 25VII-2007, C. Moresco s.n. (HUEM16527); idem, Córrego Nazaré, foz, 02-VII-2007, C. Moresco s.n. (HUEM16519).

Família Surirellaceae

Stenopterobia schweickerdtii (Cholnocky) Brassac, Ludwig \& Torgan, Diatom Research 18(1): 186, fig. 1-9, 2003. $\equiv$ Surirella schweickerdtii Cholnoky, Bot. Not. 3: 290, fig. 95-96, 1954.

Figuras 76-77

Valvas linear-lanceoladas; extremidades arredondadas; área axial linear, estreita; canais aliformes paralelos; estrias inconspícuas. Eixo apical: 160-199 $\mu \mathrm{m}$, eixo transapical: 6-7,5 $\mu \mathrm{m}, 4-5$ canais aliformes em $10 \mu \mathrm{m}$.

Ecologia: abundante na cabeceira e no meio do córrego rural ( $\mathrm{pH}$ : 6,39 a 6,64, condutividade: 98,3 a $115,3 \mu \mathrm{S} \mathrm{cm}^{-1}, \mathrm{DBO}_{5}: 0,04$ a 2,5 $\mathrm{mg} \mathrm{O}_{2} \mathrm{~L}^{-1}$ ).

Material selecionado: BRASIL. PARANÁ: Maringá, Córrego Remo, meio, 25-VII-2007, C. Moresco s.n. (HUEM16527). 


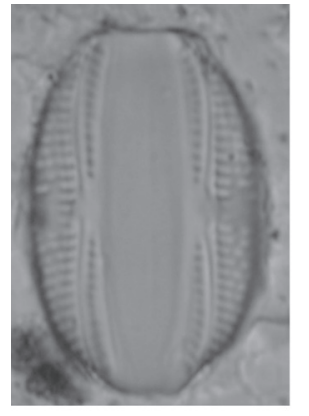

67

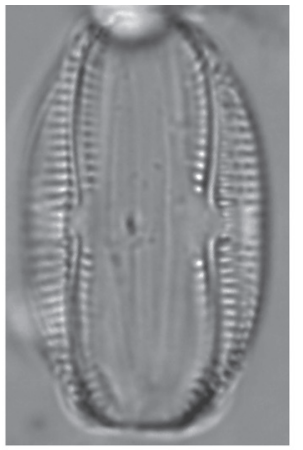

68

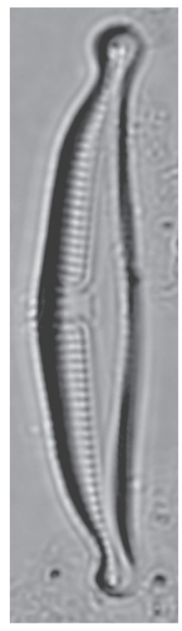

70

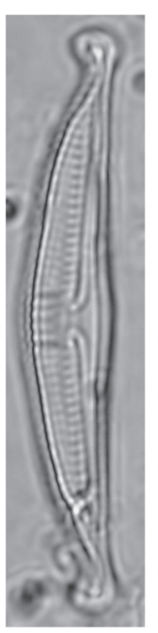

71

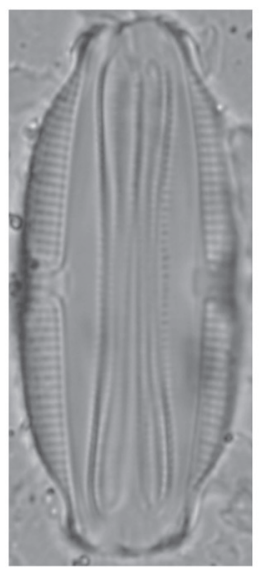

72

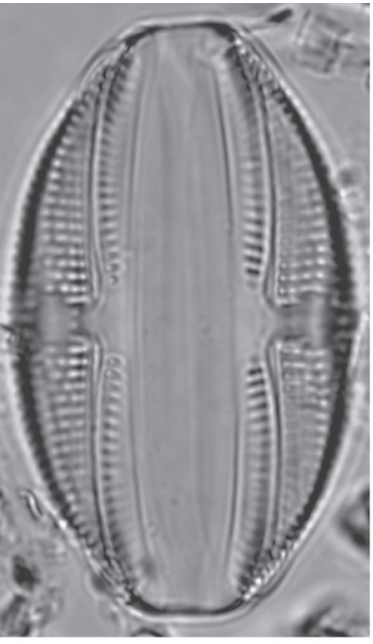

69

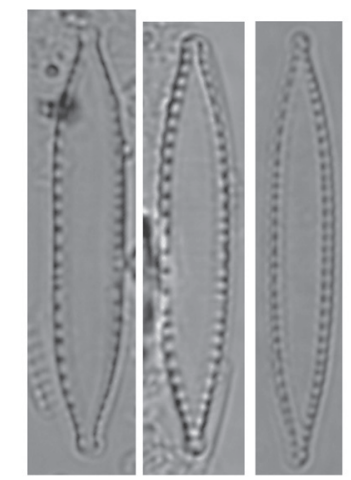

$73 . \quad 74 \quad 75$

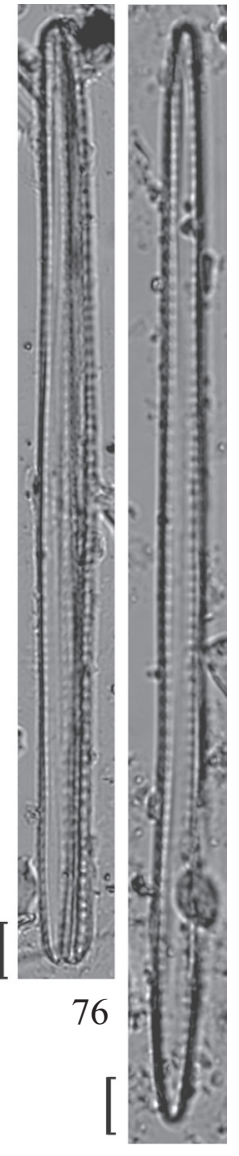

77

Figuras 67-77. 67-69. Amphora copulata. 70-72. Amphora normanii. 73-75. Nitzschia palea. 76-77. Stenopterobia schweickerdtii. Barra $=10 \mu \mathrm{m}$.

Figures 67-77. 67-69. Amphora copulata. 70-72. Amphora normanii. 73-75. Nitzschia palea. 76-77. Stenopterobia schweickerdtii. $\mathrm{Bar}=10 \mu \mathrm{m}$.

Das sete espécies de diatomáceas que foram abundantes e/ou dominantes nos três córregos, apenas uma não pode ser identificada em nível específico: Sellaphora sp. A partir dos resultados, pode inferir-se que Nupela praecipua, abundante em todos os ambientes estudados, tolera as condições de poluição provocadas pela urbanização e por alterações ocasionadas pela agricultura sobre rios e riachos. Verificou-se que o maior número de táxons predominantes ocorreu no córrego localizado na zona rural e o número de espécies abundantes/dominantes foi reduzido no córrego localizado na área urbana. Concorda-se com Chessman et al. (1999), que o aumento da área urbanizada diminui o número de espécies de diatomáceas em córregos.

Agradecimentos - Este trabalho está inserido no projeto "Identificação de potenciais bioindicadores em ecossistemas aquáticos urbanos: resposta de três grupos de organismos a gradientes de estresse”, executado pelo Núcleo de Pesquisas em Limnologia, Ictiologia e Aqüicultura, Nupélia, da Universidade Estadual de Maringá. Agradecemos em especial aos biólogos e técnicos do Nupélia, pelo suporte técnico científico, ao CNPq pelo financiamento do projeto e bolsa de produtividade em pesquisa para TAVL e LR, a Capes, pela concessão da bolsa de doutorado da primeira autora e ao Centro de Microscopia Eletrônica da Universidade Federal do Paraná.

\section{Referências bibliográficas}

ÁCS, E., RESKONE, N.M., SZABO, K., TABA, G. \& KISS, K.T. 2005. Application of epiphytic diatoms in water quality monitoring of lake Velence, Recommendations and Assignments. Acta Botanica Hungarica 47:211223. 
ALLAN, J.D. \& CASTILLO, M.M. 2007. Stream ecology: structure and function of running waters. Springer, Dordrecht.

CETESB. 1991. Norma Técnica L5.120. Demanda Bioquímica de Oxigênio (DBO), método da diluição e incubação 20 graus centígrados 5 dias. Companhia de Tecnologia e Saneamento Ambiental - Cetesb, São Paulo.

CHESSMAN, B.C., GROWNS I., CURREY, J. \& PLUNKETT-COLE, N. 1999. Predicting diatom communities at the genus level for the rapid biological assessment of rivers. Freshwater Biology 41:317-331.

FERRARI,F.\&LUDWIG,T.A.V.2007.Coscinodiscophyceae, Fragilariophyceae e Bacillariophyceae (Achnanthales) dos rios Ivaí, São João e dos Patos, bacia hidrográfica do Rio Ivaí, município de Prudentópolis, Paraná. Acta Botanica Brasilica 21:421-441.

GÓMEZ, N. \& LICURSI, M. 2001. The Pampean Diatom Index (IDP) for assessment of rivers and streams in Argentina. Aquatic Ecology 35:173-181.

GROWNS, I. 1999. Is genus or species identification of periphytic diatoms required to determine the impacts of river regulation? Journal of Applied Phycology 11: 273-283.

HALL, R.I. \& SMOL, J. 1999. Diatoms as indicators of lake eutrophication. In The diatoms: applications for the environmental and earth sciences (E.F. Stoermer \& J.P. Smol, eds.). Cambridge University Press, New York, p.128-168.

KANNEL, P.J., LEE, S., KANEL, S.R., KHAN, S.P. \& LEE, Y. 2007. Spatial-temporal variation and comparative assessment of water qualities of urban river system: a case study of river Bagmati (Nepal). Environmental Monitoring and Assessment 129:433-459.

KELlY, M.G., CAZAUBON, A., CORING, E., DELL'UOMO, A., ECTOR, L., GOLDSMITH, B., GUASH, H., HÜRLIMANN, J., JARLMAN, A., KAWECKA, B., KWANDRANS, J., LAUGASTE, R., LINDSTROM, E.A., LEITÃO, M., MARVAN, P., PADISÁK, J., PIPP, E., PRYGIEL, J., ROTT, E., SABATER, S., VAN DAM, H. \& VIZINET, J. 1998. Recommendations for the routine sampling of diatoms for water quality assessments in Europe. Journal of Applied Phycology 10:215-224.

KOBAYASI, H. \& MAYAMA, S. 1982. Most pollution tolerant diatoms of severely polluted rivers in the vicinity of Tokyo. Japanese Journal of Phycology 30:188-196.

KRAMMER, K. 2000. Pinnularia. In Diatoms of Europe (H. Lange-Bertalot, ed.). A.R.G. Gantner Verlag K.G., Ruggell, v.1, p.1-703.

KRAMMER, K. 2002. Cymbella. In Diatoms of Europe (H. Lange-Bertalot, ed.). A.R.G. Gantner Verlag K.G., Ruggell, v.3, p.1-584.

KRAMMER, K. \& LANGE-BERTALOT, H. 1986. Bacillariophyceae 1 teil: Naviculaceae. In Süßwasserflora von Mitteleuropa (H. Ettl, J. Gerloff, H. Heyning \& D. Mollenhauer, eds.). Gustav Fisher, Stuttgart, v.2/1, p.1-876.
KRAMMER, K. \& LANGE-BERTALOT, H. 1988. Bacillariophyceae 2 teil: Bacillariaceae, Epithemiaceae, Surirellaceae. In Süßwasserflora von Mitteleuropa (H. Ettl, J. Gerloff, H. Heyning \& D. Mollenhauer, eds.). Gustav Fisher, Stuttgart, v.2/1, p.1-596.

KRAMMER, K. \& LANGE-BERTALOT, H. 1991a. Bacillariophyceae 4. teil: Achnanthaceae. Kritische Ergänzungen zu Navicula (Linolatae) und Gomphonema. In Süßwasserflora von Mitteleuropa (H. Ettl, J. Gerloff, H. Heyning \& D. Mollenhauer, eds.). Gustav Fisher, Stuttgart, v.2/4, p.1-437.

KRAMMER, K. \& LANGE-BERTALOT, H. $1991 \mathrm{~b}$. Bacillariophyceae 3. teil: Centrales, Fragilariaceae, Eunotiaceae. In Süßwasserflora von Mitteleuropa (H. Ettl, J. Gerloff, H. Heyning \& D. Mollenhauer, eds.). Gustav Fisher, Stuttgart, v.2/3, p.1-576.

LANDUCCI, M. \& LUDWIG, T.A.V. 2005. Diatomáceas de rios da bacia hidrográfica litorânea, Paraná, Brasil: Coscinodiscophyceae e Fragilariophyceae. Acta Botanica Brasilica 19:345-357.

LANGE-BERTALOT, H. 2001. Navicula sensu stricto - 10 genera separated from Navicula sensu lato Frustulia. In Diatoms of Europe (H. Lange-Bertalot, ed.). A.R.G. Gantner Verlag K.G., Ruggell, v.2, p.1-526.

LEANDRINI, J.A., MOREIRA FILHO, H. \& RODRIGUES, L. 2002. Espécies perifíticas de Navicula Bory de dois sistemas lóticos do município de Maringá, estado do Paraná, Brasil. Hoehnea 29:49-56.

LOBO, E.A. \& LEIGHTON, G. 1986. Estructuras comunitarias de las fitocenosis planctónicas de los sistemas de desembocaduras de ríos y esteros de la zona central de Chile. Revista de Biologia Marina 22:1-29.

LOBO, E.A., CALLEGARO, V.L.M. \& BENDER, E.P. 2002. Utilização de algas diatomáceas epilíticas como indicadoras da qualidade da água em rios e arroios da Região Hidrográfica do Guaíba, RS, Brasil. Edunisc, Santa Cruz do Sul.

LOBO, E.A., BES, D., TUSDEQUE, L. \& ECTOR, L. 2004. Water quality assessment of the Pardinho river, RS, Brazil, using epilithic diatom assemblages and faecal coliforms as biological indicators. Vie Milieu 54:115-125.

MAACK, R. 2002. Geografia física do Estado do Paraná. Imprensa Oficial, Curitiba.

MCCORMICK, P.V. \& CAIRNS, J.J. 1994. Algae as indicators of environmental change. Journal of Applied Phycology 6:509-526.

METZELTIN, D. \& LANGE-BERTALOT, H. 1998. Tropical diatoms of South America I. About 700 predominantly rarely know or new taxa representative of the neotropical flora. Iconographia Diatomologica, A.R.G. Gantner Verlag K.G., Köningstein. v.5, p.1-695.

METZELTIN, D. \& LANGE-BERTALOT, H. 2007. Tropical diatoms of South America II. Special remarks on biogeographic disjunction. Iconographia Diatomologica, A.R.G. Gantner Verlag K.G., Köningstein. v.18, p.1-875. 
METZELTIN, D., LANGE-BERTALOT, H. \& GARCÍARODRIGUEZ, F. 2005. Diatoms of Uruguay compared with other taxa from South America and elsewhere. Iconographia Diatomologica, A.R.G. Gantner Verlag K.G., Köningstein. v.15, p.1-735.

MORALES, E.A. 2001. Fifth NAWQA Taxonomy workshop on harmonization of algal taxonomy. Report № 01-21. The Patrick Center for Environmental Research, The Academy of Natural Sciences, Philadelphia.

MOREIRA FILHO, H. \& VALENTE-MOREIRA, I.M. 1981. Avaliação taxonômica e ecológica das diatomáceas (Bacillariophyceae) epífitas em algas pluricelulares obtidas nos litorais dos Estados do Paraná, Santa Catarina e São Paulo. Boletim do Museu Botânico Municipal 47:1-17.

PAPPAS, J.L. \& STORMER, E.F. 1996. Quantitative method for determining a representative algal sample count. Journal of Phycology 32:693-696.

PATRICK, R. \& REIMER, C.W. 1966. The diatoms of the United States. Academy of Natural Sciences, Philadelphia.

PERON, A.P., CANESIN, E.A. \& CARDOSO, C.M.V. 2009. Potencial mutagênico das águas do Rio Pirapó (Apucarana, Paraná, Brasil) em células meristemáticas de raiz de Allium cepa L. Revista Brasileira de Biociências 7:155-159.

PERUÇO, J.D. 2004. Identificação das principais fontes poluidoras de afluentes da bacia do alto Rio Pirapó. Maringá. Dissertação de mestrado, Universidade Estadual de Maringá, Maringá.

POTAPOVA, M. \& CHARLES, D.F. 2007. Diatom metrics for monitoring eutrophication in rivers of the United States. Ecological Indicators 7:48-70.

QUEIROZ, D.R.E. 2003. Atlas geoambiental de Maringá: da análise à síntese, a cartografia como subsídio ao planejamento de uso e ocupação do espaço. Clichetec, Maringá.

RAMÍREZ, A., PRINGLE, C.M. \& WANTZEN, K.M. 2008. Tropical stream conservation. In Tropical Stream Ecology (D. Dudgeon, ed.). Elsevier, San Diego, p.285304.

ROUND, F.E., CRAWFORD, R.M., MANN, D.G. 1990. The diatoms, biology \& morphology of the genera. Cambridge University Press, Great Britain.

RUMRICH, U., LANGE-BERTALOT, H. \& RUMRICH, M. 2000. Diatoms of the Andes from Venezuela to Patagonia/ Tierra del Fuego and two additional contributions. Iconographia Diatomologica, A.R.G. Gantner Verlag K.G., Köningstein. v.9, p.1-673.

SALOMONI, S.E., ROCHA, O., CALLEGARO, V.L. \& LOBO, E.A. 2006. Epilithic diatoms as indicators of water quality in Gravataí river, Rio Grande do Sul, Brasil. Hydrobiologia 559:233-246.
SHEATH, R.G. \& WEHR, J.D. 2003. Introduction to freshwater algae. In Freshwater algae of North America: ecology and classification (J.D. Wehr \& R.G. Sheath, eds.). Academic Press, San Diego, p.1-9.

SIMONSEN, R. 1974. The diatom plankton of the Indian Ocean Expedition of R/V “Meteor", 1964-65 "Meteor" Forschungsergbnisse. Reihe D-Biologie 19:1-66.

STENGER-KOVÁCS, C., BUCZKÓ, K., HAJNAL, E. \& PADISÁK, J. 2007. Epiphytic, littoral diatoms as bioindicators of shallow lake trophic status: Trophic diatom index for lakes (TDIL) developed in Hungary. Hydrobiologia 589:141-154.

STEVENSON, R.J. \& PAN, Y. 1999. Assessing environmental conditions in rivers and streams with diatoms. In The diatoms: applications for the environmental and earth sciences (E.F. Stoermer \& J.P. Smol, eds.). Cambridge University Press, New York, p.11-40.

TRAIN, S. 1991. Diatomáceas (Bacillariophyceae) do córrego Moscados, Maringá, Paraná: 1. Bacillariaceae. Revista Unimar 13:299-312.

TREMARIN, P.I., LUDWIG, T.A.V., MOREIRA FILHO, H. 2008a. Eunotia Ehrenberg (Bacillariophyceae) do Rio Guaraguaçu, litoral do Paraná, Brasil. Acta Botanica Brasilica 22:845-862.

TREMARIN, P.I., LUDWIG, T.A.V. \& MOREIRA FILHO, H. 2008b. Thalassiosirales (Ochrophyta) do Rio Guaraguaçu, Bacia Litorânea Paranaense, Brasil. Acta Botanica Brasilica 22:1101-1113.

TREMARIN, P.I., LUDWIG, T.A.V., BERTOLLI, L.M., FARIA, D.M. \& COSTIN, J.C. 2009. Gomphonema Ehrenberg e Gomphosphenia Lange-Bertalot (Bacillariophyceae) do Rio Maurício, Paraná, Brazil. Biota Neotropica 9:1-20.

TREMARIN, P.I., MOREIRA FILHO, H. \& LUDWIG, T.A.V. 2010. Pinnulariceae (Bacillariophyceae) do Rio Guaraguaçu, bacia hidrográfica litorânea paranaense, Brasil. Acta Botanica Brasilica 24:330-348.

TUJI, A. 2007. Type examination of Fragilaria gracilis Oestrup (Bacillariophyceae). Bulletin of National Museum of the Natural Sciences, Series B 33:9-12.

TUJI, A. \& WILLIAMS, D.M. 2006. Examination of the type material of Synedra rumpens $=$ Fragilaria rumpens, Bacillariophyceae. Phycological Research 54: 99-103.

TUJI, A. \& WILLIAMS, D.M. 2008. Typification and type examination of Synedra familiaris Kütz. and related taxa. Diatom 24:25-29.

WALSH, C.J. 2000. Urban impacts on the ecology of receiving waters: a framework for assessment, conservation and restoration. Hydrobiologia 431:107-114.

WHITTON, B. \& KELLY, M.G. 1995. Use of algae and other plants for monitoring rivers. Australian Journal of Ecology 20:45-56. 
